\title{
Sensory Innervation of the Periodontal Ligament in the Incisor and Molar of the Monkey, Macaca fuscata. An Immunohistochemical Study for Neurofilament Protein and Glia-Specific S-100 Protein*
}

\author{
Takeyasu MAEDA \\ Department of Oral Anatomy (Prof. S. Kobayashi), Niigata University School of Dentistry, Niigata, \\ Japan
}

Received May 20, 1987

Summary. Nervous elements in the periodontal ligament of the monkey, Macaca fuscata were investigated by means of immunohistochemistry for neurofilament protein (NFP) and S-100 protein.

Thick nerve bundles with NFP-immunoreactivity entered the periodontal ligament through slits at the bottom of the alveolar socket, whereas thinner bundles, also NFP. immunoreactive, penetrated the ligament from the lateral wall of the alveolar socket. The NFP-immunopositive nerve fibers were densely distributed around the root apex in both incisors and molars. In the upper incisors, another dense distribution of NFP-positive nerves was found in the apical half of the lingual periodontal ligament and in the coronal half of the labial periodontal ligament. The periodontal nerve fibers in the incisors ramified in a dendritic fashion, terminating as free nerve endings within the periodontal ligament. Immunostaining for S-100 protein demonstrated the Schwann sheaths of nerves which showed the same distribution pattern as that of the NFP-immunopositive fibers in the periodontal ligament of the incisors.

In molars, immunostaining for NFP and S-100 showed that nerves were numerous in the apical region of the periodontal ligament. However, NFP-immunopositive nerves were fewer than the S-100-positive nervous elements in the apical region in molars. This discrepancy suggests the presence of NFP-immunonegative nerves. Immunostaining for S-100 is thus useful for demonstration of neural elements in the periodontal ligament of molars. The S-100-immunoreactive neural elements in the periodontal ligament were more numerous in incisors than in molars. In addition to the free nerve endings, a small population of coiled nerve endings was observed in the periodontal ligament of molars.

Most of the nerve fibers and cell bodies in the trigeminal ganglion showed NFP. immunoreactivity, whereas all in the mesencephalic nucleus of the trigeminal nerve were negative in NFP-reaction. This finding suggests that the periodontal ligament of molars receives a dual innervation from the trigeminal ganglion and mesencephalic nucleus.

It is well known that the periodontal ligament receives a rich sensory innervation. Accordingly, the morphological analysis of neural elements in the periodontal ligament is important for understanding the mechanism of mastication and periodontal pain (cf.

\footnotetext{
*This study was supported by a grant from the Japanese Ministry of Education, Science and Culture (No. 61790256).
} 
SCHROEDER, 1986). Furthermore, mechanoreceptors in the periodontal ligament are involved in the jaw-opening and closing reflexes (cf. MATTHEWS, 1975).

Histological studies in several different mammals on the innervation of the periodontal ligament have accumulated and revealed considerable species-differences in the distribution pattern of nerves. Only a few reports are available on the sensory innervation of human periodontal ligament, due to difficulties in obtaining intact and sufficient material from human subjects (for reviews, FEARNHEAD, 1967; STEENBERGHE, 1979; HANNAM, 1982). The teeth of the monkey should therefore be highly-favored material for understanding the innervation of human periodontal ligament. The nerve supply in the periodontal ligament of the monkey has been investigated mainly by the use of silver impregnation methods (BRADLAW, 1936, 1939; BERNICK, 1952, 1957; BERNICK and LEVY 1968; ITOH et al., 1981). Although these techniques have been able to show the distribution of nerve fibers in the periodontal ligament, they have given us little information on the nature and origin of the nerves. Moreover, as the periodontal ligament is rich in collagenous elements showing intense argyrophilia, silver impregnation of this tissue has not been conducive toward identifying nerve fibers.

Our research group has recently applied immunohistochemistry for neurofilament protein (NFP) and S-100 protein to the staining of nervous elements in the teeth and periodontal tissue, and proved that it is a useful tool for the morphological studies of the innervation of these tissues. The immunoreactions were specific enough and consistent in results even in decalcified sections (MAEDA et al., 1985, 1986, 1987; SATO et al., 1987). The purpose of the present study is to reveal the detailed distribution and terminal formation of nerve fibers in the periodontal ligament of incisors and molars in the monkey, Macaca fuscata by means of immunohistochemistry for NFP and S-100 protein.

Physiological experiments have shown that the nerve fibers in the periodontal ligament originate from the trigeminal mesencephalic nucleus, and the principal sensory nucleus and spinal trigeminal complex. The nerve fibers derived from the former are considered to be proprioceptive, while those derived from the latter are nociceptive (for reviews, STEENBERGHE, 1979; HANNAM, 1982). Keeping these possibilities on the nature of the fibers in mind, this study will also compare the NFP. immunoreactive nerve fibers in the periodontal ligament with cellular elements in the trigeminal ganglion and mesencephalic nucleus.

\section{MATERIALS AND METHODS}

\section{Antisera}

NFP antisera were raised in rabbits against each of the three subunits with molecular weights of 68000,145000 and 200000 , which were purified from rat brains according to a modification by YEN and FIELDER (1981). As our preliminary examination indicated that these three antisera showed identical staining results for neural elements in the monkey, the antiserum against the $200 \mathrm{~K}$ subunit was chosen for exclusive use in this study. The S-100 protein antiserum was raised in a rabbit by injecting a conjugate of S-100 protein purified from bovine brains and methylated bovine serum albumin. The immunological properties of this antiserum have been described in detail by MASUDA et al. (1983). 


\section{Animals}

Ten adult monkeys, Macaca fuscata, were used in this study. The animals were anesthetized with an intraperitoneal injection of pentobarbiturate $(50 \mathrm{mg} / \mathrm{kg})$ and perfused through the common carotid arteries with physiological saline, then consecutively with Bouin's fluid. The tissue blocks including first incisors or first molars were obtained from the mandibules and maxillae, and were immersed in the same fixative for 6 hrs. Following fixation, they were treated with the decalcification medium of Plank-Rychlo as reported previously (MAEDA et al., 1986). Decalcified tissues were rinsed overnight in $0.01 \mathrm{M}$ phosphate-buffered saline (PBS), pH 7.3 and were immersed in a $30 \%$ sucrose solution.

Frozen sections were prepared (20-40 $\mu \mathrm{m}$ in thickness) by use of a freezing microtome. The specimens were sectioned along three different planes (sagittal, frontal and horizontal) in order to clarify the three-dimensional distribution of nerves in the periodontal ligament.

The tissue blocks, including the trigeminal ganglia and mesencephalic nuclei were removed from the monkeys after perfusion fixation. Fixed specimens were dehydrated through graded concentrations of ethanol and embedded in paraffin. Paraffin sections were serially cut at a $4 \mu \mathrm{m}$ thickness.

\section{Immunohistochemistry for NFP and S-100 protein}

Floating sections were processed for a peroxidase-antiperoxidase (PAP) method

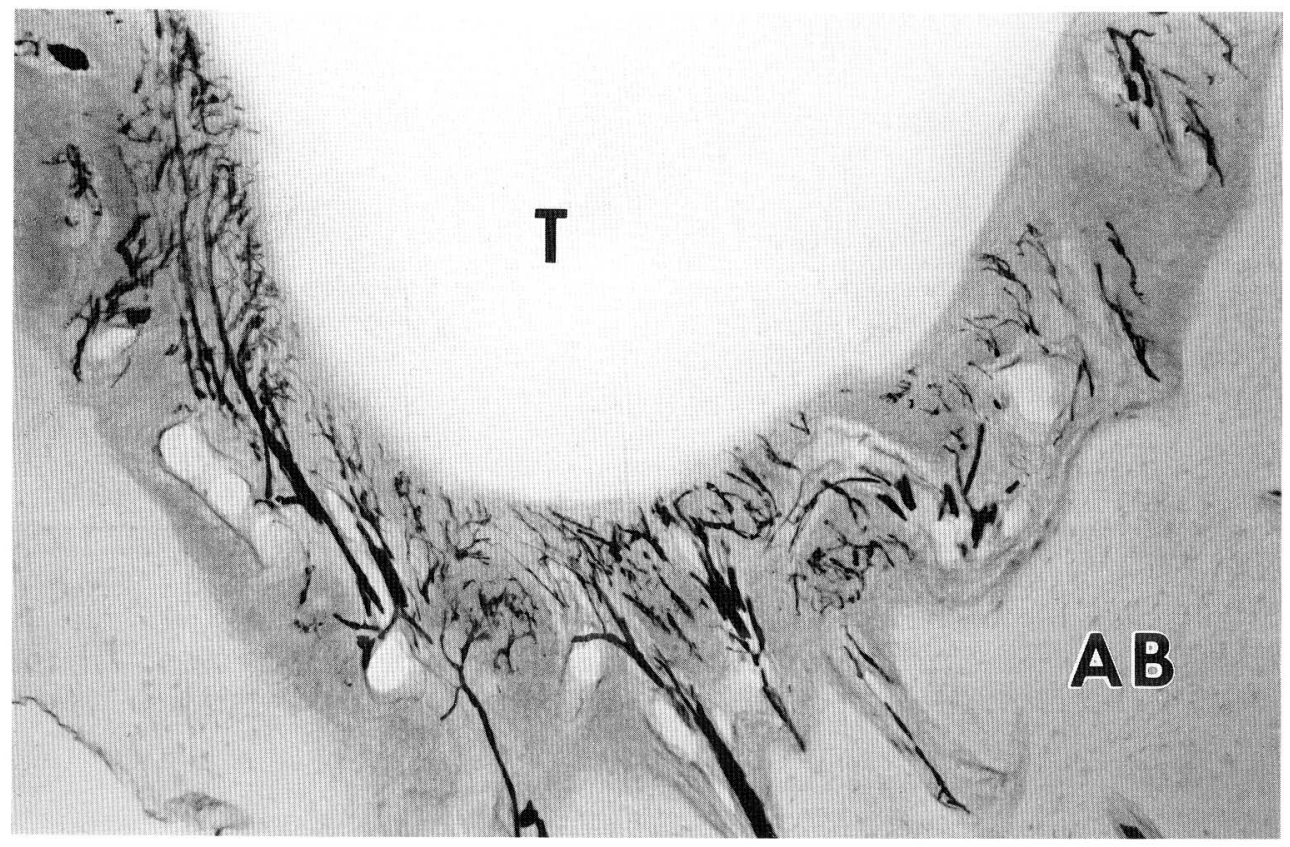

Fig. 1. The periodontal ligament of a monkey incisor. PAP-staining with NFP-antiserum. Nerve bundles showing NFP-immunoreactivity enter the periodontal ligament through slits in the bottom of the alveolar bone $(A B)$. Their branches display a dendritic ramification near the root apex. $T$ tooth. $\times 70$ 

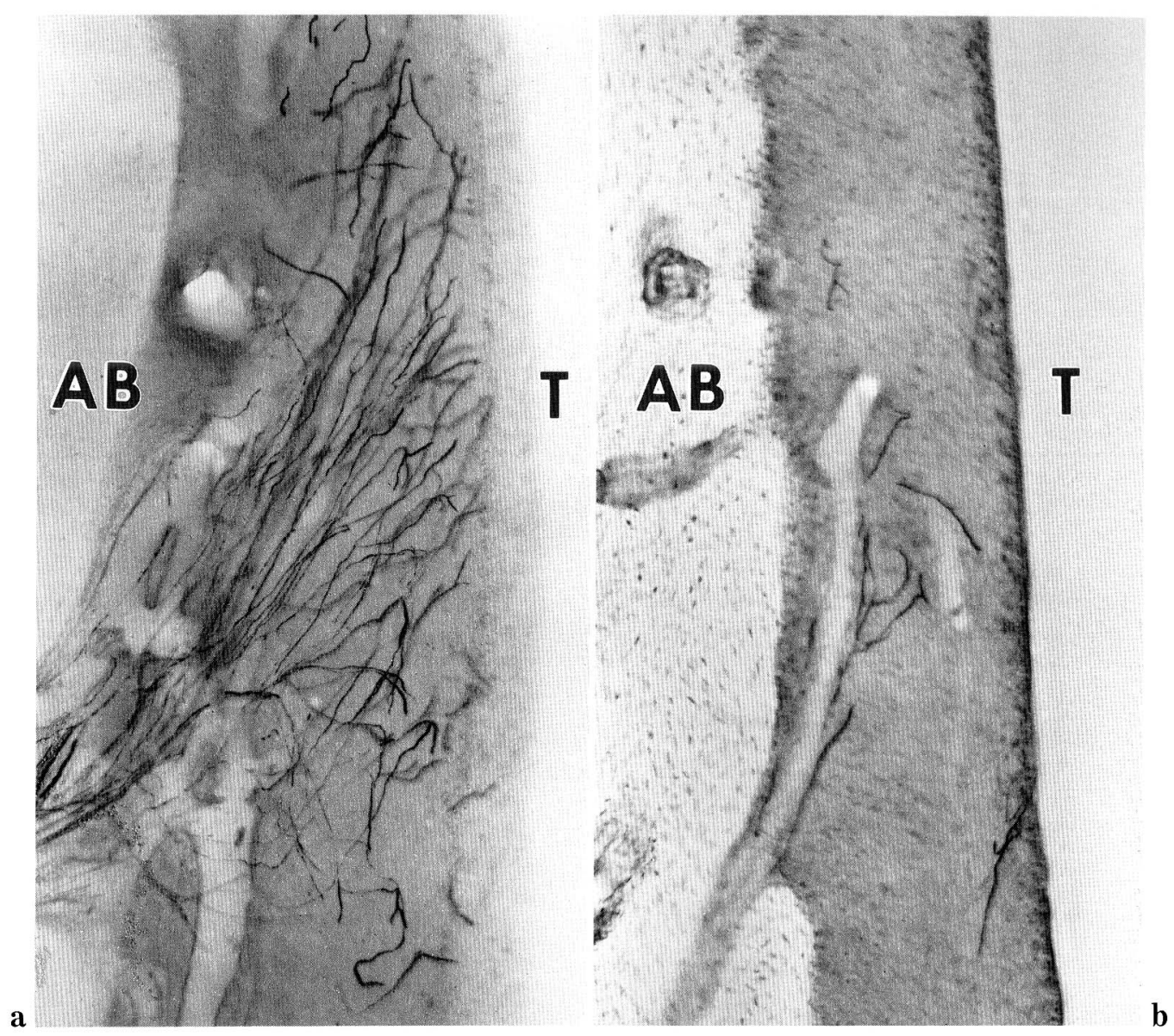

Fig. 2. a and b. NFP-immunoreactive nerve fibers in the lingual periodontal ligament of an upper incisor. Besides a concentration of nerves around the root apex, another dense distribution of NFP-positive fibers is present in the apical half of the periodontal ligament (a); a few nerve fibers can be seen in the coronal half (b) of the same section. $A B$ alveolar bone, $T$ tooth. $\times 80$

according to STERNBERGER (1979). The solution used both to dilute the antisera and to rinse the sections was PBS containing $0.3 \%$ Triton X-100. The sections were incubated overnight at room temperature with the NFP antisera or S-100 protein antiserum which were both diluted 1: 1500. After being rinsed thoroughly in PBS, the sections were incubated for $1 \mathrm{hr}$ with porcine anti-rabbit IgG (1: 60, Dakopatts, Denmmark), followed by rabbit PAP complex (1: 120, Dakopatts, Denmark). After rinsing in PBS, an enzyme reaction was developed with a mixture of diaminobenzidine tetrahydrochloride $(0.02 \%)$ and $\mathrm{H}_{2} \mathrm{O}_{2}$ in $0.05 \mathrm{M}$ Tris buffer, $\mathrm{pH}$ 7.6. Some of the immunostained sections were counterstained with hematoxylin.

Dewaxed paraffin sections from trigeminal ganglia and mesencephalic nuclei were immunostained for NFP in the same manner as mentioned above. Some were also counterstained with hematoxylin. 


\section{Specificity controls}

For checking the specificity of immunoreactions, an absorption test was performed using antisera pretreated with the corresponding antigens $(10 \mu \mathrm{g} / \mathrm{ml}$ diluted antiserum) overnight at $4^{\circ} \mathrm{C}$. The antigen-absorbed antiserum did not show any positive immunoreaction.

\section{RESULTS}

\section{Innervation of the periodontal ligament in incisors}

NFP-immunoreactive nerve bundles entered the periodontal ligament through slits of the alveolar bone, which were located at the bottom of the bony socket (Fig. 1). They soon branched in a dendritic fashion, and terminated in the vicinity of the root apex. Several thin nerve bundles from the bottom of the alveolar socket ran toward the gingiva along the lateral wall of the alveolar socket.

Other nerve bundles showing NFP-immunoreactivity entered the periodontal ligament through canals or slits which were located in the lateral wall of the alveolar socket. After entering the periodontal ligament, the NFP-positive nerve bundles were divided into two groups: ascending and descending fibers. The former branched out and ran toward the coronal portion, accompanying the climbing nerve fibers from the bottom of alveolar socket. The latter ramified to be distributed near the apical region of the incisors.

The NFP-immunoreactive nerve fibers were distributed most numerously around the root apex of both the upper and lower incisors. In the upper incisors, another dense distribution of NFP-positive nerves was present in the apical half of the lingual

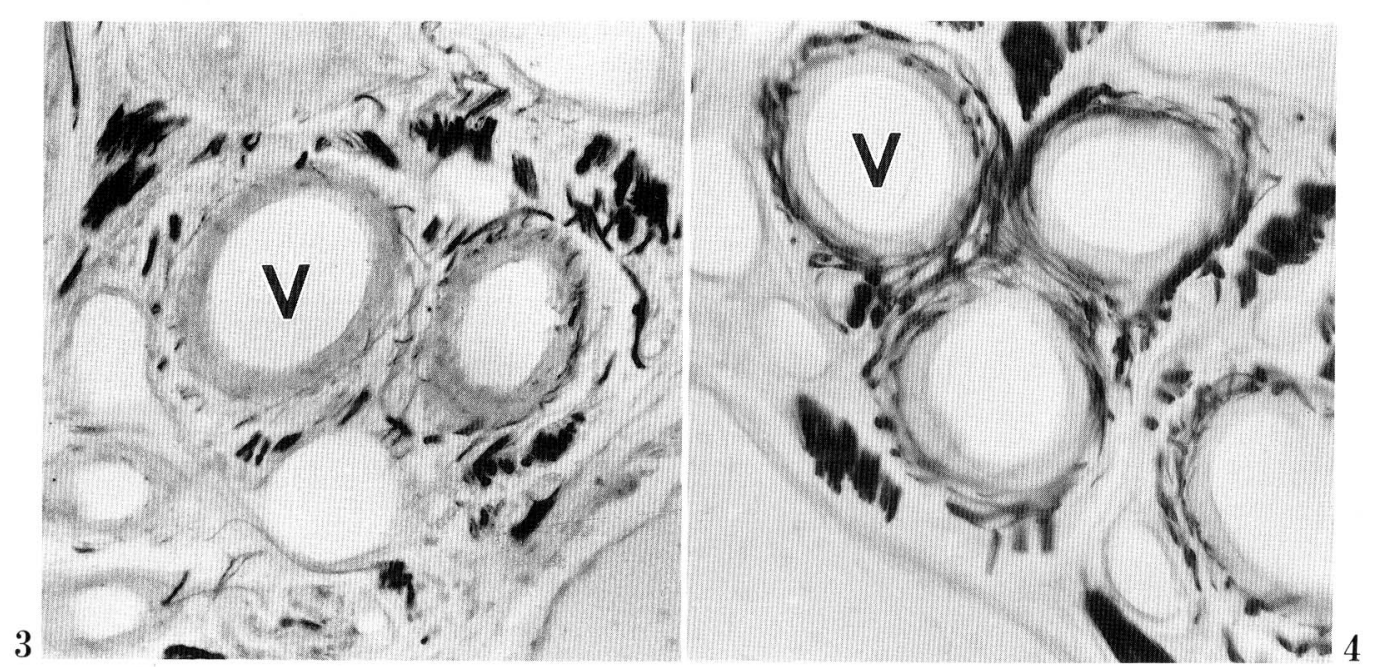

Fig. 3 and 4 . Innervation of vessels in the periodontal ligament of an incisor. A dense distribution of S-100-immunoreactive neural elements is shown around the vessels (Fig. 4). In contrast, only a few nerve fibers showing NFP-immunoreactivity surround the vessels in the adjacent section (Fig. 3). $V$ blood vessel. $\times 190$ 


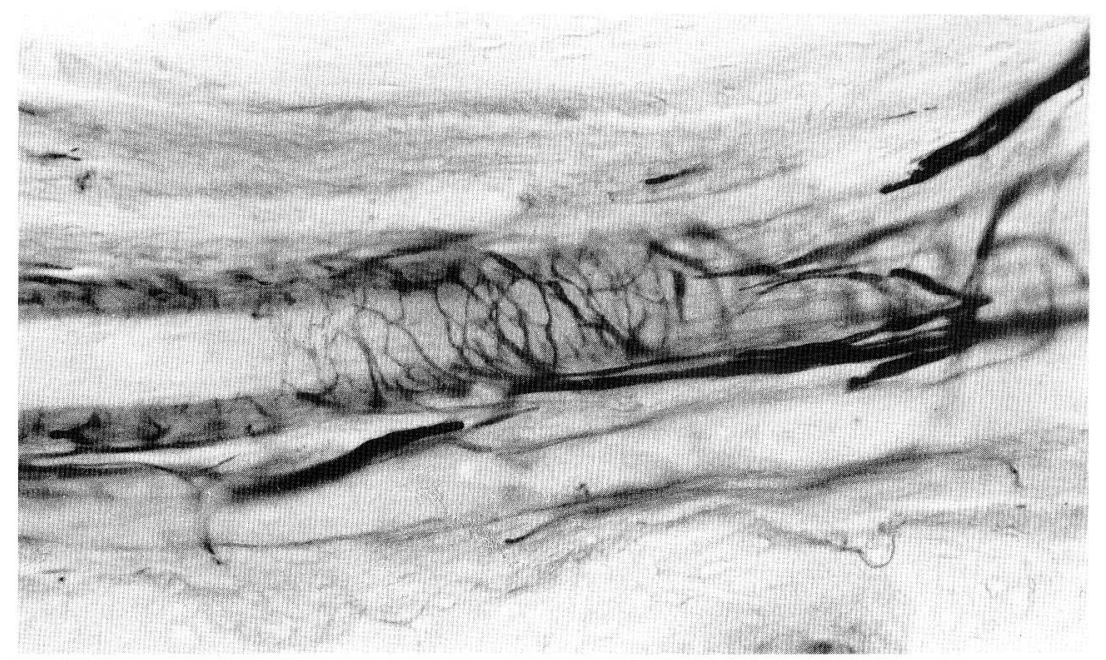

Fig. 5. A perivascular nerve plexus surrounding an artery is shown by immunostaining for S-100 protein. $\times 190$

periodontal ligament (Fig. 2a, b) and the coronal half of the labial periodontal ligament. Although such a concentration of nerve fibers as in the upper incisors was not readily evident in the periodontal ligament of the lower incisors, the nerve fibers tended to gather in the apical half of the labial periodontal ligament and the coronal half of the lingual periodontal ligament. Observation of horizontal sections showed that NFP. positive neural elements in the periodontal ligament were regularly arranged around the root. The positive nerve bundles ran in the vicinity of the alveolar wall, while single nerve fibers were distributed close to the cementum. The NFP antiserum also demonstrated nerve fibers, though less numerous, surrounding blood vessels (Fig. 3).

Most of the NFP-positive nerve fibers in the periodontal ligament displayed extensive arborization forming a dense bush-like structure, and their twigs all terminated within the periodontal fibers as free nerve endings without forming expanded portions (Fig. 6). Some of the terminals faced the cementum, and ended in the cementoblastic layer (Fig. 7). Occasionally, the nerve fibers ran transversely within the cementoblastic layer (Fig. 8, 9). No nerve fibers penetrated into the cementum. The

Fig. 6. NFP-positive periodontal nerves seen in the apical half of the periodontal ligament $(P L)$ of an incisor. They ramify repeatedly and terminate among the periodontal fibers. $T$ tooth. $\times 210$

Fig. 7. NFP-positive nerves in the apical half of the periodontal ligament $(P L)$ in an incisor. They show a tree-like ramification ending in the vicinity of the cementoblastic layer $(C B)$, and fail to enter the cementum $(C) . \times 80$

Fig. 8. and 9. NFP-immunoreactive nerve terminals in the cementoblastic layer $(C B)$ of an incisor. The nerve fibers suddenly change their direction and take a transverse course, parallel to the margin of the cementum $(C)$ (Fig. 8). In a tangentially cut section (Fig. 9), fine nerve fibers are shown to form a dendritic ramification in the cementoblastic layer $(C B)$. PL periodontal ligament. $\times 200$ 

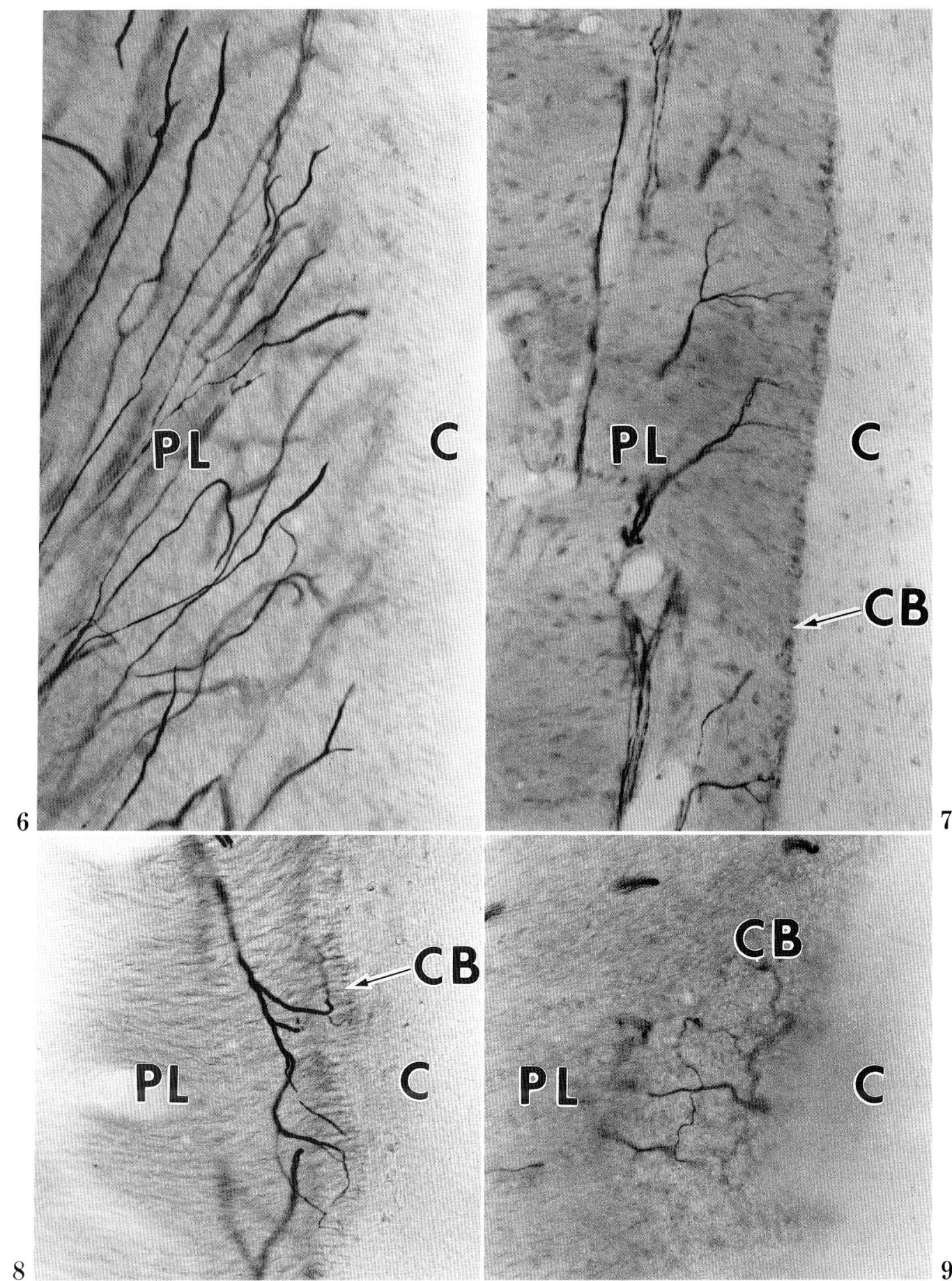

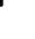



Fig. 6-9. Legends on the opposite page. 
author could not find any specialized nerve terminals such as the Ruffini corpuscles frequently observed in the periodontal ligament of rat incisors. The distribution of the NFP-immunoreactive neural elements in the periodontal ligament of the monkey incisor is summarized in Figure 10.

The S-100 protein-immunoreactive elements were also densely distributed in the periodontal ligament (Fig. 11). In the periodontal ligament of the incisors, the distribution pattern of the S-100-immunopositive elements was similar to that of the NFP. positive ones, except that the structures demonstrated with the S-100 antiserum were thicker in profile than those with the NFP antiserum (Fig. 12). No lamellated nerve terminals including Meissner's or Pacinian corpuscles immunoreacted with the S-100 antiserum.

A number of S-100 positive elements densely surrounded blood vessels of an arterial nature in the periodontal ligament (Fig. 4, 5). The cell bodies immunoreactive for S-100 occurred in the perivascular network. The S-100-positive fibers were much more numerous than the NFP-positive nerves (Fig. 3,4).

\section{Innervation of the periodontal ligament in molars}

Nerve fibers showing NFP-immunoreactivity were also observed in the periodontal ligament of molars. The periodontal ligament of molars received less numerous NFP-positive nerve fibers than that of incisors throughout the whole range of the ligament (Fig. 13). The sparsity of NFP-positive nerves in molars was prominent in the apical region of the periodontal ligament. The immunohistochemistry for S-100, however, succeeded in demonstrating a very dense distribution of nerves in the apical half of the periodontal ligament (Fig. 14). Therefore, the innervation of the periodontal ligament in molars should be described in terms of the S-100-positive elements as follows. The nerve bundles entered the periodontal ligament through slits both in the bottom and in the lateral wall of the alveolar socket (Fig. 14). The S-100-positive nerve bundles in the periodontal ligament ramified repeatedly, and split into nerve fasciculi. The furcation area of the periodontal ligament contained few S-100-positive nerve fibers. Most of these neural elements densely terminated around the root apex (Fig. 15), a part of them climbing up toward the gingiva. The distribution pattern of nerves in the periodontal ligament of molars was essentially identical to that in the incisors. In the periodontal ligament of molars, neural elements did not gather at any place except the apical region. There was also no difference in nerve distribution to the periodontal ligament between the upper and lower molars.

Two types of nerve endings were recognized in the periodontal ligament of molars: free endings (Fig. 16) and coiled terminals (Fig. 18). A majority of neural elements formed bush-like terminations in the vicinity of the cementum, though they never penetrated into the cementum (Fig. 16, 17). Nerve terminals of this type were distributed exclusively in the apical half of the alveolar socket. On the other hand, a few coiled nerve endings, which were shown only in the NFP-immunostaining, were scattered in the apical half of the periodontal ligament; after the nerve fibers took a relatively straight course, they began to run in very complex twists (Fig. 18). Their capsules were intensely immunoreactive to the S-100 antiserum (Fig. 19). However, no lamelated nerve terminals could be detected with the S-100 antiserum in the periodontal ligament of the molars. 
NFP-immunoreactivity in trigeminal ganglion and mesencephalic nucleus of trigeminal nerve

In the trigeminal ganglion, a major population of the cell bodies was reactive to the NFP antiserum, although the intensity of the immunoreaction varied among neurons (Fig. 20). The NFP-immunopositive material showed a granular appearance throughout the cytoplasm. Immunonegative somata counted less than $5 \%$ of all cell bodies. No relation could be found between the size of the cell bodies and the intensity of the NFP-immunoreaction. Almost all nerve fibers in the ganglion were positive in NFP-immunoreactivity, only a few being negative in reaction. In a cross section of the maxillary nerve just distal to the ganglion, a large number of nerve fibers were NFP-positive; approximately $10 \%$ of them were NFP-negative (Fig. 21).

In the mesencephalic nucleus of the trigeminal nerve, no cell bodies and nerves showed a positive immunoreactivity for NFP.

\section{DISCUSSION}

The present study demonstrated numerous NFP-immunoreactive neurons in the periodontal ligament of the monkey, although NFP-positive nerves were less numerous in the molars. The staining results obtained here agree with our previous studies showing that nerve fibers in the teeth and periodontal ligament of the rat and human, predominantly sensory in nature, were intensely immunoreactive for NFP (MAEDA et al., 1985, 1986, 1987; SATO et al., 1987). On the other hand, autonomic neurons in the periodontal ligament of

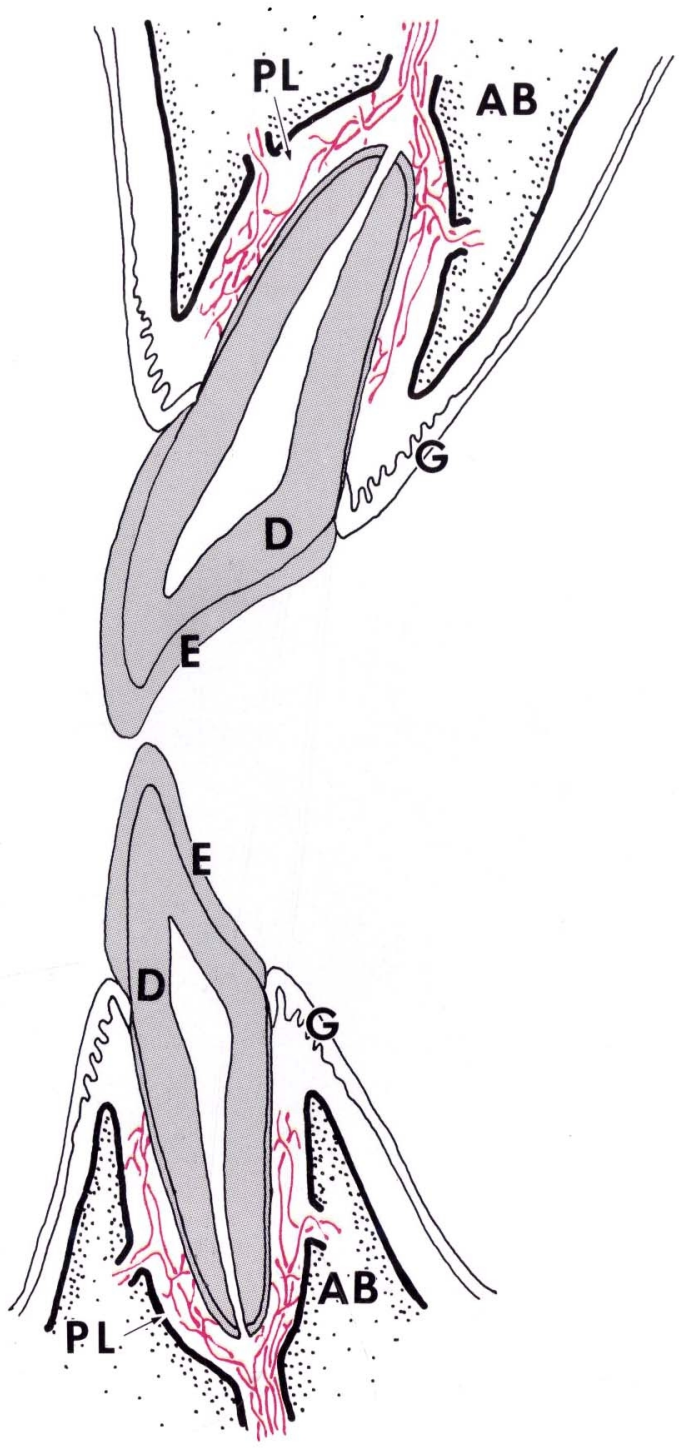

Fig. 10. Schematic representation showing the distribution of NFP-positive neural elements in the periodontal ligament $(P L)$ of incisors. A dense distribution of nerves is present in the vicinity of the root apex. NFP-positive nerves are also concentrated in the apical half of the lingual periodontal ligament and in the coronal half of the labial periodontal ligament in the upper incisor, while in the periodontal ligament of the lower incisor, a dense innervation is restricted to the root apex. $A B$ alveolar bone, $D$ dentin, $E$ enamel $G$ gingiva. 

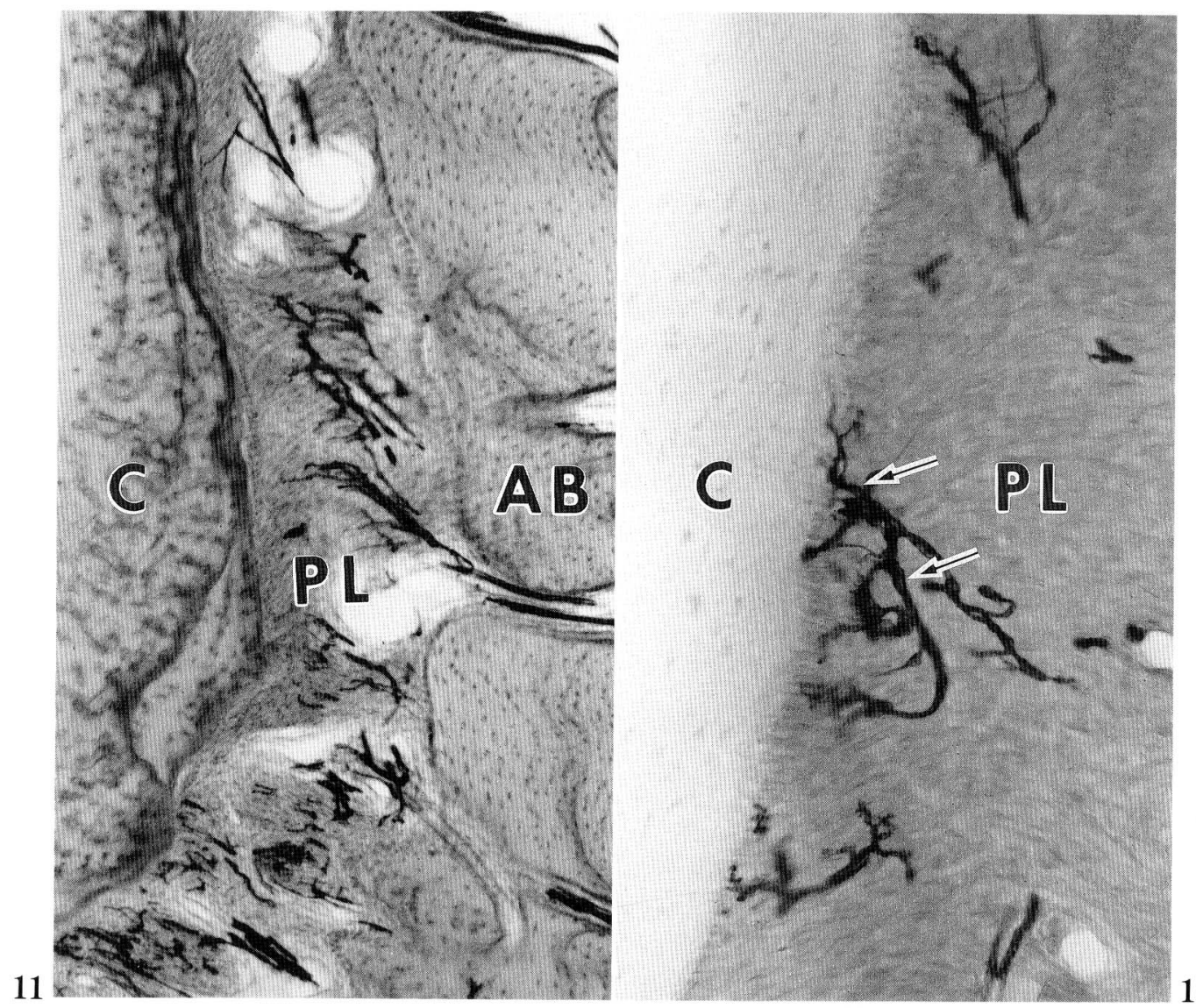

Fig. 11. The S-100-positive neural elements in the periodontal ligament $(P L)$ of the upper incisor. PAP staining followed by counterstaining with hematoxylin. Numerous S-100-positive neural elements enter the periodontal ligament through slits in the bottom of alveolar bone $(A B)$. Most of them terminate around the root apex. $C$ cementum. $\times 90$

Fig. 12. Nerve terminals showing S-100-immunoreactivity in the periodontal ligament (PL) of the upper incisor. They display a dendritic fashion and terminated near the cementum $(C)$, and do not penetrate into the cementum. Arrows indicate the nuclei of Schwann cells. $\times 200$

the monkey were negative or only weakly positive to the NFP antiserum used: Immunostaining for S-100 could demonstrate numerous neural elements innervating blood vessels, while NFP antiserum immunostained only a few nerve fibers there.

Nerve fibers have been reported to enter the periodontal ligament from both the bottom and the lateral wall of the bony socket in several mammals including the monkey (for reviews, STEEnBERGHe, 1979; Hannam, 1982). Kizior et al. (1986) designated these nerves in the cat as apical nerve fibers and alveolar nerve fibers, respectively. Such a nerve supply of the periodontal ligament was confirmed in the monkey by the present study. Early silver impregnation studies reported that sensory innervation was denser in the intermediate area than in the bottom of the alveolar socket in dogs 

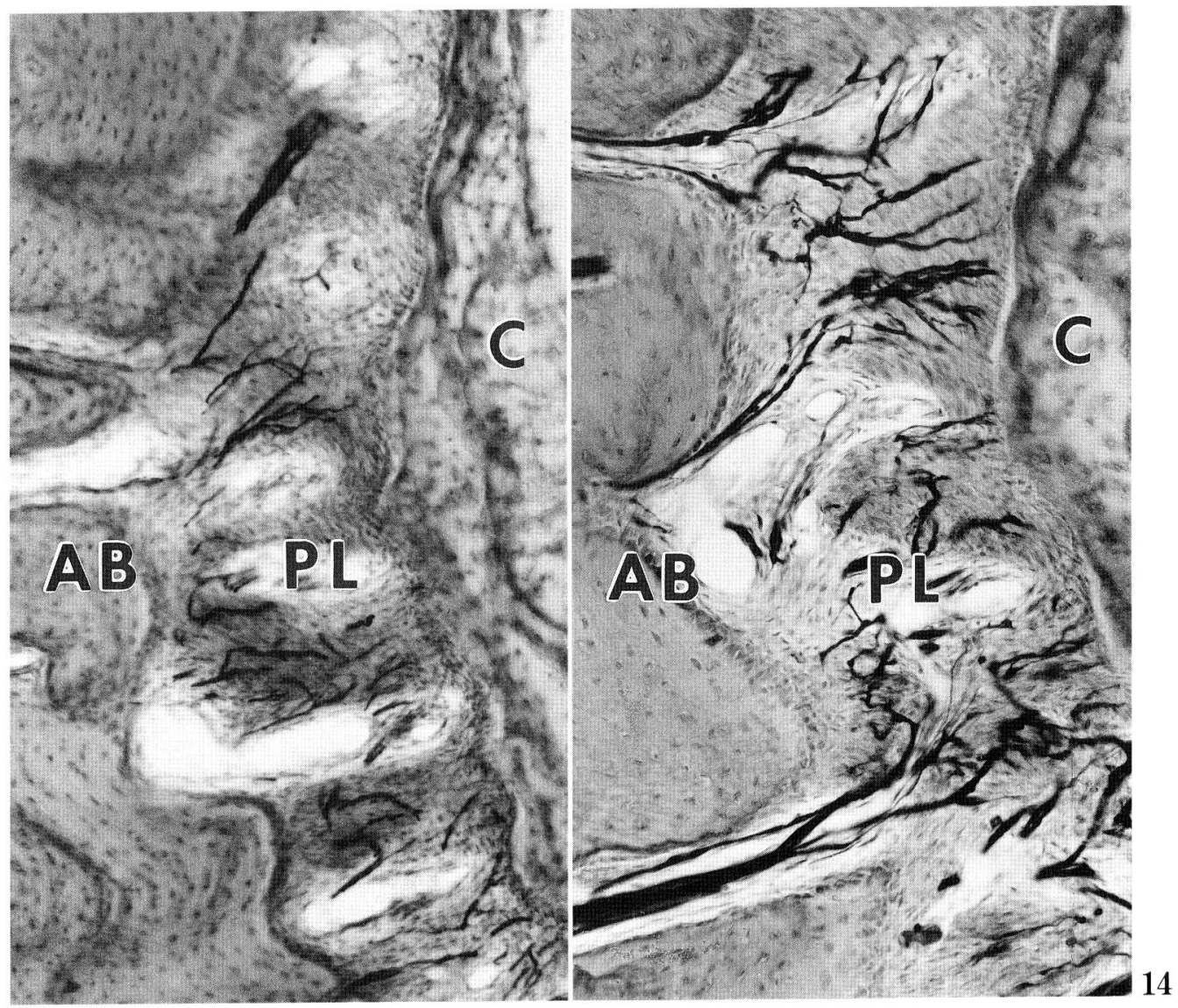

Fig. 13 and 14. A comparison of NFP- and S-100-immunopositive neural elements in the periodontal ligament $(P L)$ of a molar. In the vicinity of the root apex, the S-100immunopositive neural elements (Fig. 14) are more numerous than the NFP-positive nerve fibers (Fig. 13). $A B$ alveolar bone, $C$ cementum. $\times 80$

(OKABE, 1940) and humans (YAMAZAKI, 1948). Tokumitsu (1956) described the periodontal receptors as being distributed evenly throughout the periodontal ligament of canines and incisors in the dog. Using an axonal transport technique, ByERS (1985) reported that labeled nerve endings were about five times more numerous in the apical third than in the coronal position. Present immunohistochemical staining for NFP and S-100 has clearly revealed the richest nerve supply in the apical half of the periodontal ligament, with a poor nerve supply in the cervical half. A similar distribution pattern of NFP-positive nerves in the periodontal ligament has been observed in rat (MAEDA et al., 1987) and human molars (the author's unpublished data). Electrophysiological studies have shown that the receptors in the periodontal ligament gathered around the root apex in rabbits (Ness, 1954) and cats (PfAFFmAnn, 1939; MeI et al., 1975). It seems reasonable that a rich sensory innervation is present in the apical region of the periodontal ligament as this region receives a larger magnitude of force than elsewhere during mastication. 


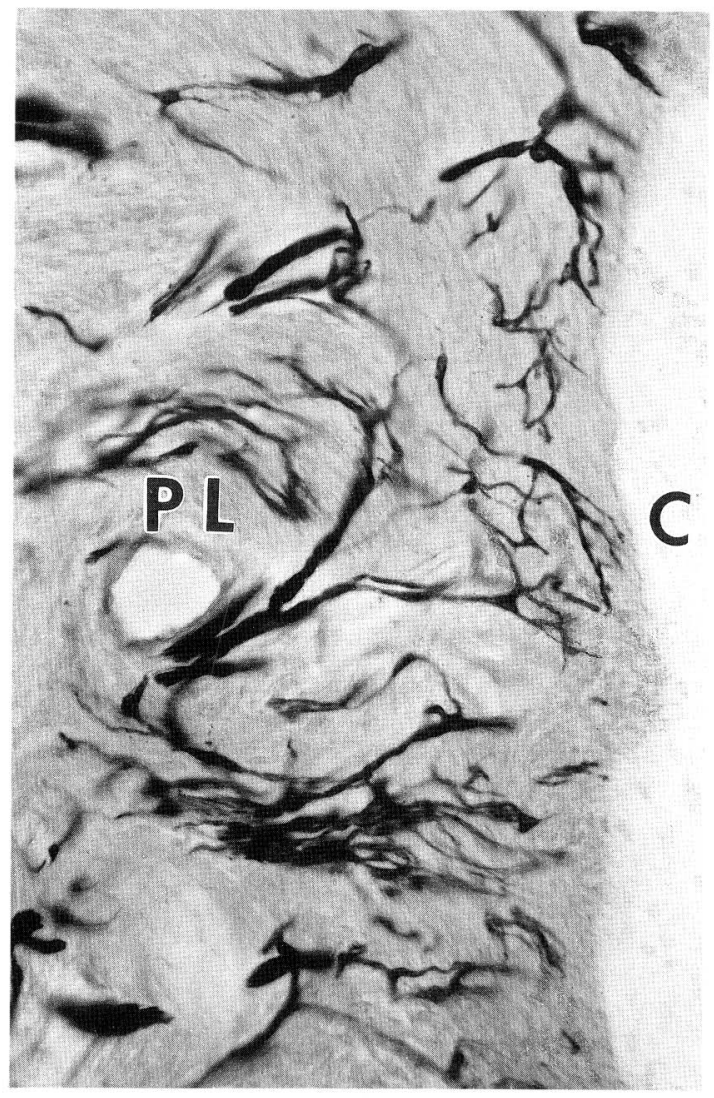

Fig. 15. The periodontal ligament in the root apex of a monkey molar, horizontal section. S-100-positive neural elements terminate in tree-like ramifications near the cementum $(C)$. PL periodontal ligament. $\times 210$

NFP-positive nerve fibers and S-100-positive glial elements have been shown to be equal in number and distribution in the dental pulp of humans and in the dental pulp and periodontal ligament of rats (MAEDA et al., 1985, 1986, 1987; SATo et al., 1987). The present study showed the existence of numerous nerve fibers in the apical region of molar periodontal ligament by alternative immunostaining for NFP and S-100 protein. In the maxillary nerve, only a small population of fibers was NFP-negative. The author failed to find a corresponding number of NFP-negative cell bodies in the trigeminal ganglion, while in the mesencephalic nucleus of the trigeminal nerve all cell bodies lacked NFP-immunoreactivity. Physiological studies have shown that the sensory neurons in the periodontal ligament of molars are derived from the trigeminal

Fig. 16. NFP-positive nerve fibers in the periodontal ligament $(P L)$ of a molar branch out and terminate within the periodontal fibers as free nerve endings. $C$ cementum. $\times 170$

Fig. 17. Dendritic S-100 neural terminals in the apical half of the periodontal ligament $(P L)$ of a molar. $C$ cementum. $\times 170$

Fig. 18. Coiled nerve ending showing NFP-immunoreactivity in the periodontal ligament $(P L)$ of a molar. $C$ cementum. $\times 230$

Fig. 19. Nerve terminal showing S-100-immunoreactivity in the periodontal ligament $(P L)$ of a molar. This corresponds to the coiled ending shown in Figure 18. C cementum. $\times 230$ 

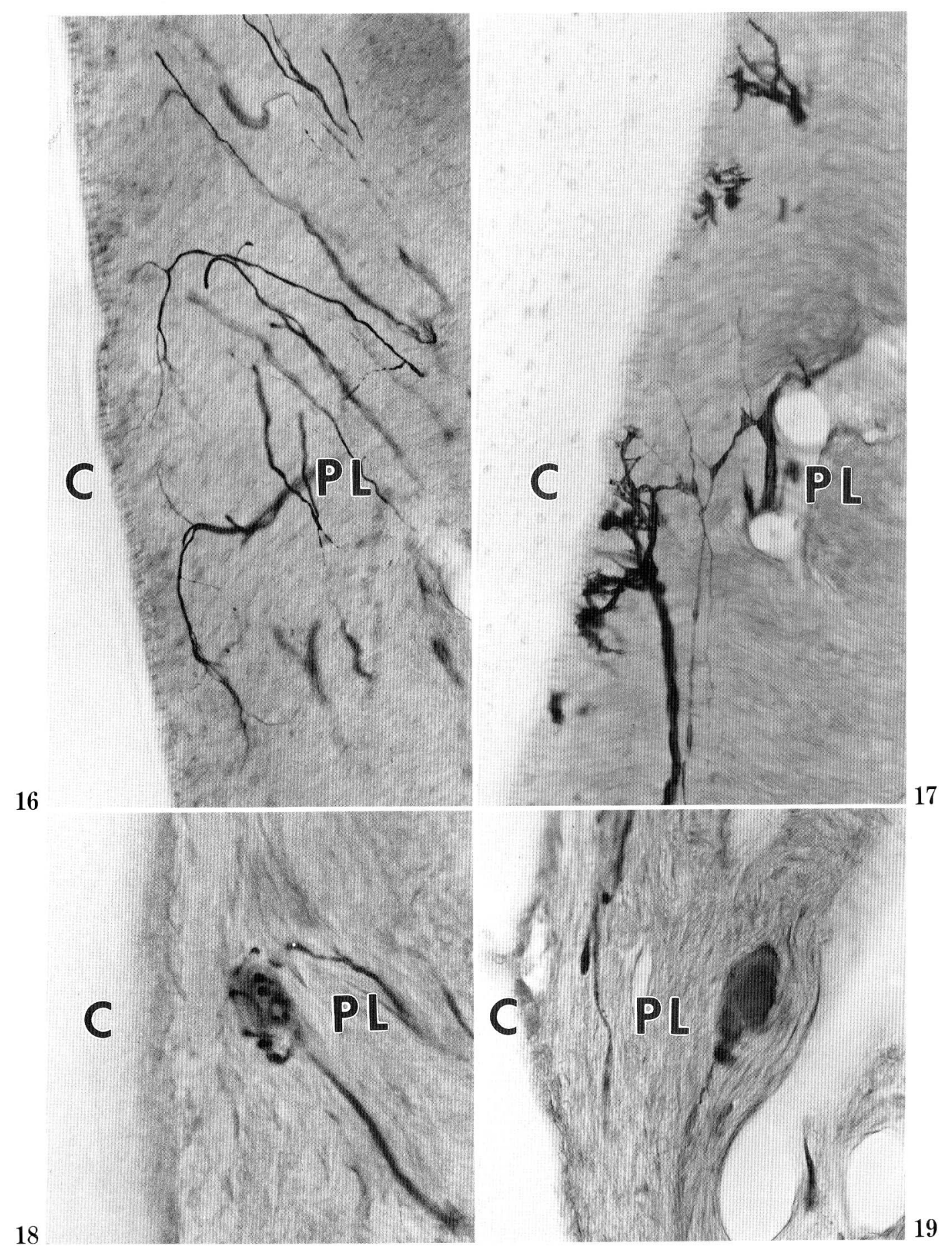

Fig. 16-19. Legends on the opposite page. 




Fig. 20. NFP-immunoreactivity in the trigeminal ganglion. Most of the cell bodies in the trigeminal ganglion are immunopositive to NFP- antiserum, although the intensity of immunoreaction is variable. Arrow indicates the NFP-immunonegative cells. $\times 190$

Fig. 21. A cross section of maxillary nerves. Almost all axons are immunopositive for NFP. Arrows indicate the NFP-negative axons. $\times 480$

mesencephalic nucleus as well as the trigeminal ganglion (JERGE, 1963; LINDEN, 1978). By injecting ${ }^{3} \mathrm{H}$-proline into the rat trigeminal ganglion, BYERS (1985), reported that labeled axons and endings amounted to $75 \%$ of the neural elements distributed in the periodontal ligament of molars. Nerve fibers originating from the trigeminal mesencephalic nucleus were distributed in the periodontal ligament around the root apex of cat canines, possibly functioning as proprioceptors (BYERS et al., 1986). Taking into consideration what has been mentioned above, NFP-negative nerves in the periodontal ligament of monkey molars are presumed to originate in the trigeminal mesencephalic nucleus which consists of NFP-negative neurons. Thus, the periodontal ligament of the molars receives dual innervation, while that of incisors is supplied exclusively by the trigeminal ganglion.

Opinions concerning nerve terminals in the periodontal ligament are in disagreement, although the receptors in the periodontal ligament are known to vary in structure and distribution according to the type of teeth or animal species (cf. ScHROEDER, 1986). Two types of nerve endings have been reported in the periodontal ligament of 
monkeys: free endings and organized or specialized terminals. BERNICK (1952) described how all the nerve fibers in the periodontal ligament of the monkey terminated as free endings, and that no specialized nerve terminals were present there. ITOH et al. (1981) found, besides free nerve endings, specialized nerve terminals resembling Meissner's corpuscles in the periodontal ligament of the crab-eating monkey. The present study demonstrates that the major population of nerve fibers terminates as free endings and a few fibers terminate in coiled-nerve endings in the periodontal ligament of monkeys.

Physiological experiments have dealt with what kind and direction of force or displacement is most effective for the receptors in the periodontal ligament. However, it remains to be elucidated whether these receptors even respond to the tension or compression of the periodontal fibers. CASH and LINDEN (1982) showed that the receptors in the cat were excited when the periodontal ligament was stretched rather than compressed. On the other hand, the periodontal receptors have been reported to respond to the compression of the periodontal ligament in the cat (PFAFFMANN, 1939) and rabbit (NESS, 1954). The present study demonstrates a dense distribution of NFP-positive nerves in the region of the upper incisors where a compressive force occurs during mastication, because the upper incisors receive mainly linguolabial pressure. This morphological finding suggests that the dendritic nerve terminals in the periodontal ligament of the monkey are reactive to compression. Some researchers believed that the regulation of mastication takes place reflexively, and regarded the periodontal tree-like nerve endings as an initial link in the reflex process (SPRENKEL, 1936; FAlin, 1958). Byers (1985) thought that the tree-like endings located deep in the periodontal ligament might respond to slight mechanical stimulation because they would be deformed easily and continuously during contact by or movement of teeth. The well-developed free endings showing tree-like terminations can be considered to function as sensory receptors in the monkey, responding to touch, vibration and mechanical distortion. The coiled endings in the periodontal ligament have also been found in the cat (KIZIOR et al., 1968) and human (RAPP et al., 1957), but not in the monkey. This type of nerve ending is frequently present in human periodontal ligament (author's unpublished data). The functional significance of these coiled endings seems to be unimportant in the monkey, because of their infrequent occurrence.

Nerve supply in the monkey periodontal ligament was denser in the incisors than in the molars as clearly shown in the immunohistochemistry for S-100. This morphological finding is in agreement with physiological and clinical experience in humans where the incisors are more sensitive to physical stimuli than the molars (MANLY et al., 1952; LOEWENSTEIN and RATHKAMP, 1955). FALIN (1958) noted that the function of the incisors in humans was characterized by a more developed tactile sense, and that man apprehends properties of food - such as its solidarity — with the aid of the incisors.

Much dispute has surrounded the penetration of sensory endings into the cementum. The silver-impregnated nerve fibers were reported to terminate in the cementum of monkeys (BERNICK, 1952; BERNICK and LEVY, 1968), and rats (BERNICK, 1956; HATTYASY, 1959). Other silver impregnation studies described that neurofibrils as entering the cementoblastic layer or there turning back toward the periodontal ligament (LEWINSKY and STEWART, 1936; RAPP et al., 1957; ITOH et al., 1981). Electron microscopic studies and autoradiographic techniques have not revealed the existence of nerve endings in the cementum of rats (PIMENIDIS and HINDS, 1977; BYERS and 
Holland, 1977; Byers, 1985), cats (Byers and Matthews, 1981) and monkeys (Byers and DonG, 1983). Our immunohistochemical study for NFP and S-100 protein was also unable to detect a penetration of nerve fibers into the cementum in rats (MAEDA et al., 1987) and monkeys (this study).

Acknowledgments. The author cordially thanks Prof. T. FujiTA and Dr. T. IwanagA, Department of Anatomy, Niigata University School of Medicine, for their kind suggestions and encouragement throughout his immunohistochemical studies on dental innervation. He is also grateful to Prof. Y. TAKAHASHI, Department of Neuropharmacology, Niigata University, Brain Research Institute, for the generous gift of antisera and antigens. Sincere thanks are due to Mr. M. Hoshino and Mr. K. TAKeuchi, Department of Oral Anatomy, Niigata University School of Dentistry, for their technical assistance in histology and photography.

\section{REFERENCES}

Bernick, S.: Innervation of primary tooth and surrounding supporting tissues of monkeys. Anat. Rec. 113: 215-238 (1952).

: The innervation of the teeth and periodontium of the rat. Anat. Rec. 125: 185-206 (1956).

: Innervation of teeth and periodontium after enzymatic removal of collagenous elements. Oral Surg. oral Med. oral Pathol. 10: 323-332 (1957).

Bernick, S. and B. M. Levy : Studies on the biology of the periodontium of marmosets: IV. Innervation of the periodontal ligament. J. dent. Res. 47: 1158-1165 (1968).

Bradlaw, R.: The innervation of teeth. Proc. Roy. Soc. Soc. Med. 29: 507-518 (1936).

: The histology and histopathology of the dental innervation. Proc. Roy. Soc. Med. 32: 1040-1053 (1939).

Byers, M. R.: Sensory innervation of periodontal ligament of rat molars consists of encapsulated Ruffini-like mechanoreceptors and free nerve endings. J. comp. Neurol. 231: 500-518 (1985).

Byers, M. R. and W. K. Dong: Autoradiographic location of sensory nerve endings in dentin of monkey teeth. Anat. Rec. 205: 441-454 (1983).

Byers, M. R. and G. R. Holland: Trigeminal nerve endings in gingiva, junctional epithelium and periodontal ligament of rat molars as demonstrated by autoradiography. Anat. Rec. 188: 509-523 (1977).

Byers, M. R. and B. Matthews: Autoradiographic demonstration of ipsilateral and contralateral sensory nerve endings in cat dentin, pulp, and periodontium. Anat. Rec. 201: 249-260 (1981).

Byers, M. R., T. A. O'Connor, R. F. Martin and W. K. Dong: Mesencephalic trigeminal sensory neurons of cat: Axon pathways and structure of mechanoreceptive endings in periodontal ligament. J. comp. Neurol. 250: 181-191 (1986).

Cash, R. M. and R. W. A. Linden: The distribution of mechanoreceptors in the periodontal ligament of the mandibular canine tooth of the cat. J. Physiol. 330: 439-447 (1982).

Falin, L. I.: The morphology of receptors of the tooth. Acta anat. 35: 257-276 (1958).

Fearnhead, R. W.: Innervation of dental tissues. In: (ed. by) A. E. W. Miles: Structural and chemical organization of teeth. Academic Press, New York, 1967 (p. 247-281).

Hannam, A. G.: The innervation of the periodontal ligament. In: (ed. by) B. K. B. Berkovitz, B. J. Moxham and H. N. Newman: The periodontal ligament in health and disease. Pergamon Press, Oxford, 1982 (p. 173-196). 
Hattyasy, D.: Zur Frage der Innervation der Zahnwurzelhaut. Z. mikrosk. -anat. Forsch 65: 413-433 (1959).

Itoh, K., M. Wakita and S. Kobayashi: Innervation of the periodontium in the monkey. Arch. histol. jap. 44: 453-466, (1981).

Jerge, C. R.: Organization and function of the trigeminal mesencephalic neucleus. J. Neurophysiol. 26: 379-392 (1963).

Kizior, J. E., J. W. Cuzzo and D. C. Bowman: Functional and histologic assessment of the sensory innervation of the periodontal ligament of the cat. J. dent. Res. 56: 531-537 (1968).

Lewinsky, W. and D. Stewart: The innervation of the periodontal membrane. J. Anat. 71: 98-103 (1936).

Linden, R. W. A.: Properties of intraoral mechanoreceptors represented in the mesencephalic nucleus of the fifth nerve in the cat. J. Physiol. 279: 395-408 (1978).

Loewenstein, W. R. and R. Rathkamp: A study of the pressoreceptive sensitivity of the tooth. J. dent. Res. 34: 287-294 (1955).

Maeda, T., T. Iwanaga, T. Fujita and S. Kobayashi: Immunohistochemical demonstration of the nerves in human dental pulp with antisera against neurofilament protein and glia-specific S-100 protein. Arch. histol. jap. 48: 123-129 (1985). the predentin and dentin of human third molars with the use of an antiserum against neurofilament protein (NFP). Cell Tiss. Res. 243: 469-475 (1986).

Maeda, T., T. Iwanaga, Y. Takahashi, T. Fujita and S. Kobayashi: Distribution of nerve fibers immunoreactive to neurofilament protein in rat molars and periodontium. Cell Tiss. Res. 249: 13-23 (1987).

Manly, R. S., C. Pfaffmann, D. D. Lathrop and J. Keyser: Oral sensory thresholds of persons with natural and artificial dentitions. J. dent. Res. 31: 305-312 (1952).

Masuda, T., K. Sakimura, Y. Yoshida, R. Kuwano, T. Isobe, T. Okuyama and Y. Takahashi: Developmental changes in the translatable mRNA for $\beta$ subunit of S-100 protein in rat brain. Biochem. biophys. Acta 740: 249-254 (1983).

Matthews, B.: Mastication. In : (ed. by) C. L. B. Lanelle: Applied physiology of the mouth. Wrights, Bristol, 1975 (p. 199-242).

Mei, N., F. Hartmann and R. Roubein: Caracteristiques fonctionelles des méchanorécepteurs des ligaments dentaires. J. Biol. bucc. 3: 29-39 (1975).

Ness, A. R.: The mechanoreceptors of the rabbit mandibular incisor. J. Physiol. 126: 475-493 (1954).

Okabe, K.: A study of the neural endings in the dog periodontal membrane. (In Japanese). J. Jap. Stomatol. Soc. 14: 641-654 (1940).

Pfaffmann, C.: Afferent impulses from the teeth due to pressure and noxious stimulation. J. Physiol. 97: 207-219 (1939).

Pimenidis, M. Z. and J. W. Hinds: An autoradiographic study of the teeth. II. Dental pulp and periodontium. J. dent. Res. 56: 835-840 (1977).

Rapp, R., W. D. Kristine and J. K. Avery: A study of neural endings in the human gingiva and periodontal membrane. J. Can. Den. Assoc. 23: 637-647 (1957).

Sato, O., T. Maeda, S. Kobayashi, T. Iwanaga, T. Fujita and Y. Takahashi: Innervation of periodontal ligament and dental pulp in the rat incisor: An immunohistochemical investigation of neurofilament protein and glia-specific S-100 protein. Cell Tiss. Res. (1987 in press).

Schroeder, H. E.: The periodontium. In: (ed., by) A. Oksche and L. Vollrath: Handbook of microscopic Anatomy. V/5. Springer-Verlag, Berlin, 1986 (p. 208-221).

Sprenkel, H. B.: Microscopic investigation of the innervation of the tooth and its surroundings. J. Anat. 70: 233-236 (1936).

Steenberghe, D.: The structure and function of periodontal innervation. A review of the literature. J. periodont. Res. 14: 185-203 (1979). 
Sternberger, L. A.: Immunohistochemistry, 2nd ed. Prentice-Hall, Englewood Cliffs, New Jersey, New Jersey, 1979.

Tokumitsu, Y.: On the innervation, especially the sensory innervation of the periodontal membrane, the dental pulp and periosteum of the lower alveolus in dog. Arch. histol. jap. 10: 123-140 (1952).

Yamazaki, J.: On the sensory innervation of human periodontal membrane (In Japanese). Tohoku Igaku Zasshi (Sendai) 38: 7-14 (1948).

Yen, S. H. and K. L. Fielder: Antibodies to neurofilament protein, glia filament and fibroblast intermediate filament proteins bind to different cell types of the nervous system. J. Cell Biol. 88: 115-126 (1981).

前田健康

干 951 新潟市学校町通 2 番町

新潟大学歯学部

口腔解剖学第二教室
Dr. Takeyasu MAEdA

Department of Oral Anatomy

Niigata University School of Dentistry

Gakkocho-Dori-2

Niigata, 951 Japan 